\title{
Technological Growth of Fuel Efficiency in European Automobile Market 1975-2015
}

\author{
Kejia $\mathrm{Hu}^{\mathrm{a}}$, Yuche Chen*b \\ ${ }^{a}$ Kellogg School of Management, Northwestern University, Evanston, IL, 60208 \\ ${ }^{b}$ National Renewable Energy Laboratory, 15013 Denver West Parkway, Golden, CO 80401 \\ Yuche.Chen@nrel.gov
}

\begin{abstract}
This paper looks at the technological growth of new car fleet fuel efficiency in the European Union between 1975 and 2015. According to the analysis results, from1975 to 2006 the fuel efficiency technology improvements were largely offset by vehicles' increased weight, engine size, and consumer amenities such as acceleration capacity. After 2006, downsizing in weight and engine capacity was observed in new car fleet, while fuel consumption decreased by $32 \%$ between 2006 and 2015 . We adopt a statistical method and find that from 1975 to 2015 , a $1 \%$ increase in weight would result in 0.3 to $0.5 \%$ increments in fuel consumption per $100 \mathrm{~km}$, and a $1 \%$ reduction in $0-100 \mathrm{~km} / \mathrm{h}$ acceleration time would increase fuel consumption by about $0.3 \%$. Impacts of other attributes on fuel consumption are also assessed. To meet the European Union's 2021 fuel consumption target, downsizing of cars, as well as at least maintaining fuel efficiency technology growth trend observed between 2005 and 2015, are needed. Government policies on controlling improvement in acceleration performance or promoting alternative fuel vehicles are also important to achieve European Union 2021 target.
\end{abstract}

\section{Keywords:}

Fuel consumption, Technology development, New cars 


\section{Introduction}

The transportation sector is a major energy consumer and one of the largest Greenhouse Gas (GHG) emission contributors. Governments around the world are taking steps to address the energy and GHG emission problems caused by transportation (CARB, 2009; US DOE, 2009; EU, 2011; Chen and Fan, 2013; Zhang et al., 2016; Chen, et al., 2015). In 2009, the European Union (EU) government finalized setting emission performance standards for new passenger cars as part of the EU Community's integrated approach to reduce carbon dioxide (CO2) emissions from light-duty vehicles (EU, 2009). This regulation sets the average $\mathrm{CO} 2$ emissions for new passenger cars at $130 \mathrm{~g} \mathrm{CO} 2 / \mathrm{km}$ (equivalent to 5.6 liters per 100 $\mathrm{km}$ of gasoline or 4.9 liters per $100 \mathrm{~km}$ of diesel) by end of 2015, and $95 \mathrm{~g} \mathrm{CO} 2$ / km (equivalent to 4.1 liters per $100 \mathrm{~km}$ of gasoline or 3.6 liters per $100 \mathrm{~km}$ of diesel) by 2021.

According to European Environment Agency (EEA), the average fuel efficiency level of a new car sold in 2014 was 5.3 liters per $100 \mathrm{~km}$, which was already below the 2015 target of 5.6 (EEA, 2015). Although manufacturers have made considerable technological progress, they still have to do more in order to meet 4.1 liters per $100 \mathrm{~km}$ by 2021. For policymakers and researchers, it is important to know whether the 2021 target is achievable and to be aware of whether the candidate polices can help smoothing the process.

Generally, influencing factors of vehicle fuel efficiency, usually expressed as fuel consumption (FC) per distance of vehicle travel, can be put into three categories, i.e. vehicle system inputs (e.g. vehicle weight, engine attributes, body shape), vehicle system outputs or consumer amenities (e.g. acceleration performance, all-wheel drive feature), and technological progress in vehicle fuel efficiency. Here, the technological progress is a measure of innovations that help vehicles achieve better fuel efficiency without changing any vehicle system input and output parameters. Otherwise, without technological improvement, the only way to achieve a lower fuel consumption rate is through downsizing vehicle system input parameters, or limiting consumer amenities. Furthermore, the three factors interact with each other. For example, engine size (vehicle system input) influences acceleration performance (vehicle system output), and these two are both impacted by technological development because with advanced 
technology, vehicles can achieve better acceleration performance without changing engine size. Therefore, in order to predict the fuel efficiency of future cars, we need to 1) quantify relationships between vehicle input / output parameters and fuel efficiency, 2) understand the historical technological improvement in fuel efficiency of cars.

As summarized by MacKenzie and Heywood (2015), there are two major views of evaluating fuel efficiency in vehicles, the bottom-up and top-down view. The bottom-up view focuses on the relationship between vehicle system inputs (such as engine attributes, weight, etc.) and fuel consumption, while the top-down view focuses on vehicle system outputs (performances perceived by consumers, such as acceleration time).

Extensive studies were devoted to utilize the bottom-up approach (Kwon, 2006; Van den Brink and Van Wee, 2001; Knittel, 2011). Kwon (2006) investigated the quantitative relationship between engine capacity and fuel consumption rate in the UK between 1979 and 2000. It was found that technological improvements during that period were mainly used to offset increased average engine capacity in the 1980s. Van den Brink and Van Wee (2001) quantified impacts of weight, cylinder capacity on Dutch new car-fleet fuel consumption using the bottom-up approach. Similar to the findings of Kwon (2006), it was concluded that the unchanged new car-fleet fuel consumption between 1985 and 1997 was mainly due to the fact that the benefits of technological improvement were used to offset increased engine capacity and weight. Knittel (2011) adopted a similar bottom-up approach to study trade-offs between engine power, vehicle weight, and fuel economy in the US. It was found that technological progress that occurred between 1980 and 2006 had the potential to increase fuel economy by $65 \%$. However, due to increase in vehicle weight and engine power, the actual increase in fuel economy was only $18 \%$, only one fourth of the potential.

Although the bottom-up approach is easy to understand and backed by continuous engineering efforts, it is hard to predict the adoption time of new technologies, which leads to the difficulty in assessing future 
vehicle fuel efficiency. This is because the adoption of technologies depends on consumers' choices. Therefore, recent research efforts have been shifted to utilize the top-down approach, which focuses on vehicle performances perceived by consumers.

Sprei and Karlsson (2013a and 2013b) found that until 2007, in Sweden, majority of technological development in the energy efficiency of cars was offset by continuously enhanced consumer amenities. But between 2007 and 2010, consumer amenities remained flat and, therefore, technological development resulted in actual reduction in fuel consumption. MacKenzie and Heywood (2015) adopted Knittel's (2011) econometric approach but included both vehicle system attributes and consumer amenities as independent variables. They found that per-mile fuel consumption could have been reduced by about $70 \%$ from 1975 to 2009 , holding the acceleration performance and functionality of vehicles unchanged.

Although the top-down approach has the advantage of easily assessing future technological progress through consumers' amenities choices, it is also has disadvantages. Long term series of consumer amenity choice data are difficult to obtain. In addition, it is hard to predict consumers' amenities preferences. This paper takes a step in incorporating the bottom-up and top-down approaches into a methodological framework and further examines our models' interpretability in the European automobile industry.

The objectives of this paper are to 1) study the relationship between fuel consumption, vehicle attributes, and consumer amenities; 2) quantify the historical rates of fuel efficiency technology improvement in European cars, and 3) compare the improvement rates with those of US cars. The knowledge established in this study can further be used to understand whether or not, and how, the EU can achieve its fuel efficiency targets in 2021. This study distinguishes itself by its inclusion of vehicle system input parameters and consumer amenities in explaining vehicle fuel consumption rate, and the estimating of historical technological progress in one model framework. 
The rest of the paper is organized as follows: methodology is presented in section 2 . The data source and summary statistics are discussed in section 3 . The results are detailed in section 4 . The conclusion and policy implications are presented in section 5 and section 6 respectively.

\section{Methodology}

There are several candidate methods that can be used for conducting analysis to achieve the objectives of this paper. Engineering-based powertrain simulation is one solution. Usually a powertrain simulation tool is built that takes vehicle design, engine control technology, and other vehicle attributes as inputs and estimates fuel efficiency of vehicles (Gao et al., 2015a; Gao et al., 2015b; Chen and Meier, 2016). Several publicly available tools are out there, such as FASTSim, Autonomie (Brook et al., 2015; Halbach et al., 2010; Morrison and Chen, 2011; Chen and Fan, 2014), and some previous studies were conducted using this approach (Vijayagopal and Rousseau, 2011; Moawad et al., 2014; Borken-Kleefeld and Chen, 2015; Chen and Borken-Kleefeld, 2014; Chen and Borken-Kleefeld, 2016). However, in this paper, our purposes include both studying impacts of vehicle attributes on fuel consumption and investigating technological progress trends of fuel efficiency in EU cars. The engineering simulation approach could not provide technological progress trends, which is an important aspect to predict fuel efficiency. Another approach is called econometric modeling. This is the approach chosen by Knittel (2012) and MacKenzie (2015). It has the advantage of quantitatively estimating of relationship between fuel consumption and vehicle attributes, as well as being able to utilize large volume, multi-year panel data to investigate technological progress trends of fuel efficiency. Therefore, an empirical multi-variate model, similar to the model specified in Knittle (2011) and MacKenzie and Heywood (2015), is adopted in this study. Similar to previous studies, Cobb-Douglas function form is used to model the relationship between fuel consumption and vehicle attributes. The basic setup of the econometric model is as following:

$$
\ln F C_{i t}=T_{t}+\beta_{1} \ln w_{i t}+\beta_{2} \ln T 100_{i t}+\boldsymbol{X}_{i t}^{\prime} \boldsymbol{B}+\epsilon_{i t}
$$


Where $F C_{\mathrm{it}}$ is the fuel consumption in unit of liter per $100 \mathrm{~km}$ for car model $i$ in year $t . T_{t}$ is a fixed effect term trying to estimate time dependent technological improvement in our panel data ${ }^{1} \cdot w_{\mathrm{it}}$ is its curb weight, and $\mathrm{T} 100_{i t}$ is its 0 to $100 \mathrm{~km}$ per hour acceleration time in seconds. $\boldsymbol{X}_{\mathrm{it}}$ is a vector of other variables representing amenities of vehicles, such as whether the vehicle has a manual transmission, whether it is a two-seater or a wagon body style, or other powertrain type. These variables are proved to influence fuel consumption by previous studies. In addition, we consider interactions between some variables and time, for example, whether manual transmission fuel efficiency impact changes as time evolving. This will be discussed in details in the analysis section. The name of variables and their definitions are in the Table 1:

\section{INSERT [Table 1]}

In total, there are five models each includes different combination of variables defined above (referring to Table 3). And we will explain the models in details in the results section.

\section{Data}

The data used to estimate the model in this paper were obtained from the European Union vehicle catalog ${ }^{2}$. The dataset has detailed information on fuel consumption rate per $100 \mathrm{~km}$, vehicle characteristics, engine attributes, and other consumer amenities (such as acceleration performance, allwheel drive feature) for all new cars offered in the European Union in each year between 1975 and 2015. In this study, we only focus on passenger cars ${ }^{3}$. The number of newly offered passenger car models ranges from 300 to 800 in each year. The total number of record is about 18,000 which are all used to run the estimation model introduced in Methodology section ${ }^{4}$. It is important to point out that all cars offered

\footnotetext{
${ }^{1}$ A realization of fuel efficiency technological improvement between year $t$ and year $t$ ' is the difference in fuel consumption of two average cars each from year $t$ and $t^{\prime}$, mathematically it is captured as $\frac{F C_{t}}{F C_{t^{\prime}}}=e^{T_{t}-T^{\prime}} t^{\prime}$. ${ }^{2} \mathrm{http}: / /$ www.auto-data.net/en/. This is a website providing technical specifications and fuel consumption information of automobiles offered for sale in Europe from year 1975 to 2015.

${ }^{3}$ According to 2002/24/EC of March 2002 and 2007/46/EC, passenger car is a vehicle designed and constructed for the carriage of passengers and having a maximum mass not exceeding 3.5 tons.

${ }^{4}$ Note that the average fuel consumption calculated here is the average of cars offered in EU market. It does not equal to the real-world average fuel consumption of cars on EU roads, which requires to be weighted by sales statistics as well as VMT statistics by car models. However, the average fuel consumption of cars offered can still be
} 
in EU do not cover all cars in all EU member states, particularly those importing cars from regions out of EU. But by studying all cars offered in EU, we can draw conclusions regarding general trend of technological improvement in majority of cars in EU.

Before discussing the econometric model results, we present summary statistics of the data. Table 2 reports the summary statistics for vehicles across the entire sample, and particularly for 1985, 2002, 2006 and 2015. The listed statistics in specific years enable comparison with Swedish numbers (Sprei et al., 2013a and 2013b) and US numbers (Knittel, 2011) from previous literatures.

\section{INSERT [Table 2]}

The average fuel consumption is 7.32 liter of gasoline equivalent per $100 \mathrm{~km}$ for passenger cars. Note that we convert diesel consumption to gasoline equivalent using the ratio specified in EU passenger car GHG emission regulation (EU, 2009). This way, in the remaining of this paper, we only need to discuss fuel efficiency in unit of gasoline consumption. The average fuel consumption of vehicles offered in 1985 , 2002, 2006 and 2015 are 8.45, 8.89, 8.27 and 5.61 liters per $100 \mathrm{~km}$. In the two decades period of 19852006, the fuel consumption rates fluctuated and did not show any decrease ${ }^{5}$. This observation is consistent with findings in Netherlands (Van den Brink and Van Wee, 2001), UK (Kwon, 2001), and Sweden (Sprei et al., 2008; Sprei and Karlsson, 2013a). But in the recent decade, we observe a 32\% reduction in fuel consumption rate of cars offered in the market, from 8.27 to 5.61 liters per $100 \mathrm{~km}$. In the meanwhile, the average passenger car fuel consumption rates in US market for 1985, 2006 and 2015 are 10.28, 8.68 and 6.88 respectively (Knittle, 2012; FHWA, 2015). The FC rates of US and EU cars might not be directly comparable due to the differences in testing cycles, but at least we have two inferences. Firstly, from 1985

utilized to study trends of fuel efficiency of cars alone the years, which is the same approach adopted by studies in US (Knittle (2011), MacKenzie and Heywood (2015)), UK (Kwon (2006)).

${ }^{5}$ Note that these average fuel consumption rates are not equivalent to sales-weighted average fuel consumption rates, therefore, it is possible to be skewed by the increase of large cars (larger in engine size, heavier in weight). But the summary statistics still can show the trend of cars' fuel consumption rates in EU, and can be compared with majority of other studies in US and EU member states, because those studies adopted similar approach in calculating average fuel consumption rates. 
to 2006, FC rates of EU did not change too much, but FC rates in US had experienced a downward trend. Secondly, from 2006 to 2015, FC rates have been reduced more in EU (32\% reduction) compared with US $(21 \%)$. Again, note that the average fuel consumption rate is calculated based on information of vehicles offered in the market, not the actual fleet average. But in general the fleet average fuel consumption rate will follow the trend of vehicles offered in the market.

From 1985 to 2006, although the average FC remained relatively stable, other vehicle attributes increased significantly. For example, average curb weight increased by $10 \%$, engine power almost doubled, volume of engine increased by $12 \%$ and torque increased by $50 \%$. In the meantime, in terms of consumers amnesties, 0 to $100 \mathrm{kmph}$ acceleration time was reduced by $30 \%$ and more newly offered cars were diesel powered ( 7 folders), with manual-transmission ( 2.5 folders) and all-wheel drive ( 6.5 folders) features. Clearly, we see an upsizing of both vehicle system input attributes as well as consumer amenities. Therefore, it is possible that the technological progresses during this time period were used to offset upsized cars, thus resulted in no improvement in fuel consumption.

On the other hand, an average passenger car in 2015 was lighter (5\% weight reduction), had smaller engine (20\% reduction in engine volume and 2\% reduction in engine power) compared with those of 2006. Even though the acceleration performance was improved by $7 \%$ and torque was increased by $11 \%$, we still observe a clear downsizing trend in cars offered in the market. In addition, diesel cars got more popularity increasing number of diesel car models were offered in the market. The downsizing effect, increased diesel cars alone with technology development are the major contributors of the $32 \%$ reduction in FC rates observed in the period. The trends of FC rates and vehicle attributes witnessed here provide good initial thoughts on explaining the relationship between FC rates and attributes as well as the technology development in the last four decades. But we need an econometric model to further quantify the parameters. 


\section{Result}

\subsection{Model Estimate Results}

A comprehensive EU cars dataset is used to run the estimation model. The dataset is comprised of detailed information on fuel consumption rate per $100 \mathrm{~km}$, vehicle attributes, and other consumer amenities for about 18,000 new passenger car models offered in EU between 1975 and 2015. Table 3 presents estimates of the five different models' specifications ${ }^{6}$. The estimated coefficients and standard deviation (in parentheses) are provided. The significance tests show that majority of coefficients are significant at $99.9 \%$ confidence level. Every model includes a fixed year effect, i.e. the degree of technological progress. Each year will have a unique estimate and the difference between two years can indicate the technological progress between the two years ${ }^{7}$. But for the sake of brevity, the estimates for fixed year effects are omitted even though they all statistically significant at 99.9 percent confidence level.

\section{INSERT [Table 3]}

Model 1's results are similar in magnitude but opposite in sign to the results of Knittel's model 1. This is because Knittel used log of fuel economy as dependent variable, while our work uses log of fuel consumption rate as the dependent variable. To make the comparison with Knittel's results more convenient, we convert changes in fuel economy into fuel consumption rate. Our coefficients show that $1 \%$ increase in weight or engine horsepower could result in $0.31 \%$ or $0.30 \%$ increase in fuel consumption, whereas the numbers from Knittel's study were $0.40 \%$ or $0.33 \%$ increase in fuel consumption. The fixed effect estimates between 1980 and 2006 is equal to -0.38 , i.e. $32 \%$ in potential fuel consumption rate reduction by holding other attributes constant in Model 1. This is lower than the results reported by Knittel (40\% potential fuel consumption rate reduction) in the same time period. Van den Brink and Van Wee (2001) estimated similar technology development in Netherlands and concluded that $13.4 \%$ potential

\footnotetext{
${ }^{6}$ Please refer to supplement information (SI) document for heteroscedasticity and collinearity tests of the models. Most of the tests proved the validity of the models.

${ }^{7}$ For example, in Model 1, the fixed year effects for 1975 and 2015 were -1.364 and -1.886 respectively. So, holding vehicle weight and horsepower constant, the fuel consumption rate of an average car in 2015 is only $59.3 \%$ of that in 1975 , i.e. the technological progress leads to $40.7 \%$ reduction in fuel consumption. The $59.3 \%$ is calculated because from equation (1), $\frac{F C_{2015}}{F C_{1975}}=e^{-1.886-(-1.364)}=e^{-0.523}=59.3 \%$
} 
reduction in fuel consumption rate in Netherlands from 1985 to 1997. And our model 1 shows a very close estimate of $11.6 \%$ for the same timeframe.

Model 2 replaces acceleration time with horsepower as an explanatory variable. This change leads to two important changes. First, it increases the sensitivity of fuel consumption to weight. This observation is expected and consistent with findings by MacKenzie and Heywood (2015). The explanation is that increasing weight at constant acceleration time will require extra fuel consumption to account for the weight change as well as power change in order to keep acceleration time unchanged. Secondly, it significantly reduces sensitivity of fuel consumption to manual transmission, i.e. having a manual transmission in model 2 will result in less fuel consumption rate reduction compared with model 1.

Model 3 is similar to model 3 of Mackenzie and Heywood (2015). It controls for consumer amenities related attributes, namely all-wheel drive (AWD), acceleration performance and vehicle body styles. Comparing with Mackenzie and Heywood's results, we find that European cars' sensitivity of fuel consumption to weight is less than that of US cars ( $1 \%$ increase in weight results in $0.26 \%$ increase in fuel efficiency in European cars versus $0.65 \%$ in US cars). In the meanwhile, European cars' sensitivity of fuel consumption to acceleration time was also less than that of US cars. A two seater is leading to $12 \%$ FC increase in European cars compared with $4 \%$ in US cars. A wagon makes less FC increase in Europe compared with U.S. cars. Another notable change in Model 3 the AWD feature will make the vehicle consuming more fuel but the effect is diminishing with technology progress in this feature.

Model 4 is similar to model 1 in most of setup but replaces horsepower with several engine-related attributes, e.g. bore, compression ratio, stroke, torque, and volume of engine. This change in model setup makes turbo diesel engine statistically not significant to influence fuel consumption rate. But the added engine related attributes are all significant at $95 \%$ confidence level. This model has a slightly higher adjusted R-square which also means model 4 interprets the data better than model 1 . 
Model 5 is structured by reintroducing consumer amenities into model 4 . The estimated coefficients of weight and engine-related attributes changed when the consumer amenities are included in the model. This suggests overlooked correlations between weight or engine-related attributes with consumer amenities in model 4. Estimates of technology development reflected in the year fixed effects are increased in model 5. This observation is expected and consistent with the idea that when consumer amenities are not explicitly controlled for, the technology development will be offset by the increased consumer amenities. Hence, when consumer amenities are explicitly included as explanatory variables, technology development offset by enhanced consumer amenities will be recovered and shows in the year fixed effects.

Comparing the five models, it is apparently that, if we do not account for consumer amenities and engine attributes, estimation biases will be observed in analyzing tradeoffs between fuel consumption and vehicle attributes. Therefore, model 5 is the preferred model specification among the explored models in this study. In addition, model 5 has the greatest explaining power with the greatest adjusted $\mathrm{R}^{2}$ value among the five models.

\subsection{Technological progress}

The technological progress (i.e. year fixed effect) coefficients are different for different years and are all statistically significant at $99.9 \%$ confidence level. We assemble actual FC rates of new European cars, and several potential average new cars' FC to illustrate the technological progress under different setups (see Figure 1). The red line is the actual FC of new cars in European market. The green line represents expected year-to-year average new cars' FC, considering estimated technology improvements and holding engine power and vehicle weight at 1975 levels (Model 1 in Table 2). The red line is generated based on fixed year effect coefficients of Model 1. The blue line represents the new cars' FC trajectory if acceleration performance, weight, and share of offered cars with wagon, manual transmission, two-seater, and other special powertrain features remained at 1975 levels (Model 3 in Table 2). Lastly, the green line represents the expected new cars' FC trajectory if engine attributes, weight, and share of offered cars with 
wagon, manual transmission, two-seater, and other special powertrain features were unchanged since 1975 (Model 5 in Table 2). In Figure 1, we also add United States' potential FC holding weight and power unchanged (dashed red line), and potential FC holding weight and acceleration performance unchanged (dashed blue line) for comparison purpose. The data are obtained from previous US studies using similar model specifications (MacKenzie and Heywood, 2015; Knittle, 2011).

\section{INSERT [Figure 1]}

- If power and weight had remained unchanged, FC of cars could have been reduced by $40 \%$ between 1975 and 2015. We compare our results with similar studies conducted in some countries in Europe and detail the comparison results in the next section.

- If weight and acceleration performance remain unchanged, FC of cars could have been reduced by $45 \%$ between 1975 and 2015 in Europe. This means improvements in engine technology to deliver the same acceleration with lower power contributed about 5\% FC reduction over the period.

- If weight and engine attributes had remained unchanged, FC of cars could have been reduced by $25 \%$ between 1975 and 2015. But in reality, the average FC of new cars offered have been reduced by $36 \%$ with simultaneously increased average vehicle weight and more powerful engine attributes. This again confirms that European car manufacturers have successfully made large progresses in engine technologies to help reduce vehicles' FC.

- Between 1975 and 2015, the actual fuel consumption rate of the average new car was reduced by $36 \%$.

It is important to note that the improvements in fuel consumption rate did not occur consistently over time. Between 1975 and 2005, the potential reduction in FC holding weight, engine attributes and amenities fluctuated and showed no noticeable improvement. But between 2005 and 2015, we have witnessed a solid improvement in fuel efficiency technology with an average annual improvement rate of $2.8 \%$. This 
result again confirms the observation in the data summary section, which is the technological development in Europe is different from that of US. The US cars technology development has been observed consistently since 1975, with a more rapid rate in 1975-1990 and slowed growth in 1990-2009 (MacKenzie and Heywood, 2015).

As shown in Figure 1, the actual average FC of offered cars in Europe is 5.61 liters per $100 \mathrm{~km}$ in 2015. The EU's target by year 2021 is 4.1 liters per $100 \mathrm{~km}$, i.e. another $27 \%$ reduction in FC rate or annual reduction rate of 5\%. The 2021 target seems very aggressive because the 5\% annual reduction rate in FC has never been observed in history, even for the period 2005-2015 when we have seen solid progress. We will discuss in details regarding possible policies to help Europe achieve the 2021 target in the Policy Implication section.

\subsection{Comparison of technological improvements with previous studies}

We compare the technological improvement reported in this paper with estimates from analogous earlier studies. Across European countries, other researchers studied the potential reductions in fuel consumption that could have been achieved if holding other vehicle attributes unchanged. But other than time periods, methodologies and controlling vehicle attributes varied among those studies. Table 4 summarizes some of these studies.

\section{INSERT [TABLE 4]}

All of the literature estimates are larger than the estimates presented in this study. This is because our model controls most of variables related to cars attributes and amenities, whereas other studies listed in Table 4 only controlled for some of variables. Therefore, the technological progress estimated by the compared studies included progress in variables not controlled. For example, Van den Brink and Van Wee (2001) estimated technological progress rate in Netherlands as 1.3\% per year from 1985 to 1997, which is higher than the $0.7 \%$ rate estimated by our study for the same period. But Van den Brink and Van Wee (2001) only controlled for cars' weight and engine size. Therefore, their technological progress rate included the increasing penetration of high fuel-efficient diesel cars and other variables not controlled for. 
Our results show that in Europe, if holding all vehicle attributes (engine size, weight, features and performances) constant, the potential fuel consumption rate for an average 2006 model year vehicle is $20 \%$ lower than that of an average vehicle made in 1980. And the potential fuel consumption rate for an average model year 2009 vehicle is $27 \%$ lower than that of a model year 1975 vehicle.

These potential reductions are lower than the $40 \%$ and $50 \%$ for US cars as estimated by Knittel (2012) for period 1980-2006 and MacKenzie and Heywood (2015) for period 1975-2009. This is explained by the fact that European cars' power and weight had not increased as quickly as US cars in the past three decades, although they shared similar weight and power in 1980. Particularly, during the 1980-2006 periods, US cars' average engine power had increased $123 \%$ whereas the increase of engine power for European cars was only $62 \%$. Therefore, European carmakers were not as much motivated as US carmakers to aggressively develop technologies to offset the impacts of upsized vehicle attributes on fuel efficiency.

\section{Conclusion}

In this study, we investigate two problems: 1) the relationship between a vehicle's fuel consumption, vehicle attributes, as well as consumer amenities; 2) the historical rates of fuel efficiency technology improvement in European cars compared to improvement rates with those of US cars. We adopt an econometric approach to study the relationship and technological progress trends, and then use the EU new car database in the empirical analysis. The results show that in Europe, from 1975 to 2015, a 1\% increase in weight yielded $0.21 \%-0.58 \%$ increase in fuel consumption rate, depending on the model specifications. It also shows that $1 \%$ improvement in acceleration performance yielded about $0.3 \%$ increase in fuel consumption rate during the same period. In addition, other attributes' influences on fuel consumption are also observed.

Although technological progresses were observed during 1975-2005, the technological progress was mainly used to offset fuel efficiency impacts of increased engine power, consumer amenities and 
acceleration performance. Holding vehicle weight and engine power at the year 1975's level, the fuel consumption rate could have been reduced $17 \%$ in 2005 . Holding vehicle weight and 0 to $100 \mathrm{kmph}$ acceleration time at the 1975 level, the FC rate reduction would have be $18 \%$ in year 2005. This confirms that small improvement in engine's ability to turn power to acceleration performance happened between the 1975-2005 period. In addition, holding vehicle weight, engine attributes and consumer amenities at the 1975 level, the FC rate could only have been reduced by 4\%. This observation demonstrated that significant technology progress was realized in tuning engine and generating more power given the same engine attributes.

From 2005 to 2015, solid improvement in fuel efficiency of new cars, with an annual reduction rate of $4.1 \%$, was observed. By holding vehicle weight and engine power at the 2005 level, the average car's FC rate could have been reduced by only $3.7 \%$ annually.

We also compare our results with earlier studies in some European countries and find that the results are consistent. By comparing our results with results of US studies, we find technology development patterns differ in US and Europe automobile market. In the US, fuel efficiency technologies rapidly developed in earlier years, but slowed down in recent years. But the technology progress in the European automobile market experienced a slow start from 1980 to 2005, though in recent decades, we have observed solid developments.

\section{Policy Implication}

Our analysis and other studies show that over the past three decades, vehicle fuel efficiency technologies in Europe's automobile market have been developed significantly. However, due to lack of regulation, part of the technology development benefits were used to enhance vehicle weight, acceleration performance, and other consumer amenities without sacrificing fuel efficiency. Even though the European Union's fuel efficiency target for 2015 was already met, to achieve the 2021 goal is still challenging and 
cannot be satisfied if relying on current fuel efficiency improvement trend. Rather, it needs a portfolio approach that includes both continuation of technology development and policies on downsizing weight, engine power, or acceleration performance of vehicles.

From 2015's target, we need another $27 \%$ reduction in fuel consumption rate to reach the target in 2021 (i.e. 5\% annual reduction rate). We have shown that, during period 2005-2015, a technological progress trend with an annual reduction rate of $4.4 \%$ was achieved (if holding weight and acceleration performance unchanged). If we can maintain the technological improvement trend observed in 2005-2015, we only need another $0.6 \%$ reduction annually to satisfy the target by 2021 . This can be achieved by the continuation of downsizing in vehicle weight and acceleration performance. Our data shows that the average vehicle weight of cars offered had been reduced by $0.6 \%$ annually during the period of 2005 2015. If the vehicle weight downsizing trend observed in 2005-2015 continues till 2021, we will be at $4.7 \%$ annual reduction rate (using coefficients from Model 2 results in Table 3), very close to the 5\% target. The other $0.3 \%$ annual reduction rate can come from a downgrade in acceleration performance. However, as we have observed in Table 2, the acceleration performance has been increased by $0.8 \%$ annually in the past ten years. This is the area where government policies need to emphasize the control of further growth in acceleration performance to help achieve the target by 2021 . With a $1 \%$ annual decrease in acceleration performance, we will be able to achieve the $5 \%$ annual reduction rate on average fuel consumption by 2021.

It is worth pointing out that the fuel consumption rate data we obtained in this study are window-sticker type of values, based on fuel efficiency testing on certified driving cycles, such as the New European Driving Cycle (EC, 2014). Recently, increasing attention has been given to discrepancies between typeapproval and real-world fuel consumption rates (Tietge et al., 2015; Pavlovic et al., 2016). A recent report from the International Council on Clean Transportation found that although official average fuel consumption rates of new passenger cars in the EU declined 28\% from 2001 to 2014, in reality fuel consumption rates in everyday operation did not decline as much as these official statistics would seem to 
indicate (Tietge et al., 2015). Specifically, Tietge et al. found that the divergence between real-world and type-approval fuel consumption rates increased from $8 \%$ in 2001 to $40 \%$ in 2014 . If this holds, it means that the reduced fuel consumption rates observed in our dataset would not lead to any benefits during real driving situations, but rather results of car companies' optimization for the type-approval test cycles or the unrealistic conditions of the test cycles. However, this situation might be ended soon because, starting from 2017, the EU is introducing real driving emissions (RDE) tests using portable measurement systems. This is to ensure that the measurements better reflect emissions and energy consumptions in real driving conditions (EC, 2014). It is definitely important to re-evaluate the results and conclusions of this study after 2017 using the new real-world fuel consumption rates to assess real technological progresses.

\section{Acknowledgments}

YC was supported by the U.S. Department of Energy under Contract No. DE-AC36-08GO28308 with the National Renewable Energy Laboratory. The authors would like to thank the two anonymous reviewers' comments and suggestions. 


\section{Reference}

An, F., DeCicco, J., 2007. Trends in technical efficiency trade-offs for the US light vehicle fleet. SAE technical paper 2007-01-1325.

An, F., Ross, M., 1993. A model of fuel economy and driving patterns. SAE technical paper 1993-0328.

Argonne National Laboratory, 2009. Welcome to Autonomie: Math-based plug-and-play software for automotive system design. http://www.autonomie.net/pdfs/AutonomieBrochure_3.25.09.pdf Accessed on June $1^{\text {st }}, 2016$.

Borken-Kleefeld, J., Chen, Y., 2015. New emission deterioration rates for gasoline cars - Results from long-term measurements. Atmospheric Environment, 101, 58-64.

Breusch, T. S., Pagan, A. R., 1979. A simple test for heteroscedasticity and random coefficient variation. Econometrica 47 (5), pp. 1287-1294.

Brook, A., Gonder, J., Wang, L., Wood, E., 2015. FASTSim: A model to estimate vehicle efficiency, cost and performance. SAE Technical Paper 2015-01-0973. doi: 10.4271/2015-01-0973.

CARB. Zero Emission Vehicle Program. http://www.arb.ca.gov/msprog/zevprog/zevprog.htm (accessed May 11, 2014).

Chen, Y.; Fan, Y., 2013. Transportation Fuel Portfolio Deisgn under Envolving Technology and Regulation: A California Case Study. Transportation Research Part D, 24, 76-82.

Chen, Y.; Fan, Y., 2014. Coping with technology uncertainty in transportation fuel portfolio design. Transportation Research Part D, 32, 354-361.

Chen, Y., Borken-Kleefeld, J., 2014. Real-driving emissions from cars and light commercial vehicles

- Results from 13 years remote sensing at Zurich/ch. Atmospheric Environment, 88, pp. 157-164.

Chen, Y., Borken-Kleefeld, J., 2016. NOx emission from diesel cars worsen with age. Environmental Science \& Technology.

Chen, Y., Meier, A., 2016. Fuel Consumption Impacts of Auto Roof Racks. Energy Policy.

Chen, Y., Young, S., Gonder, J., Qi, X., 2015. Estimate of Fuel Consumption and GHG Emission Impact on an Automated Mobility District. The Proceedings of $4^{\text {th }}$ International Conference on Connected Vehicles \& Expo.

Energy, U. S. D. o. One MILLION Electric Vehicles By 2015.

https://www1.eere.energy.gov/vehiclesandfuels/pdfs/1_million_electric_vehicles_rpt.pdf (accessed May 11, 2014).

European Environment Agency, 2015. New cars' CO2 emissions well below Europe's 2015 target. http://www.eea.europa.eu/highlights/new-cars2019-co2-emissions-well Accessed on March 1st, 2016. 
European Environment Agency, 2014. Regulation (EC) No 333/2014 of the European Parliament and of the Council of 11 March 2014 amending Regulation (EC) No 443/2009 to define the modalities for reaching the 2020 target to reduce $\mathrm{CO} 2$ emissions from new passenger cars.

http://data.europa.eu/eli/reg/2014/333/oj

European Union, 2009. Regulation (EC) No 443/2009 of the European Parliament: setting emission performance standards for new passenger cars as part of the Community's integrated approach to reduce $\mathrm{CO} 2$ emissions from light-duty vehicles.

Gao, Z., Smith, D.E., Daw, C.S., Edwards, D.K., Kaul, B.C., Domingo, N., Parks II, J.E., Jones, P.T., 2015a. The evaluation of developing vehicle technologies on the fuel economy of long-haul trucks. Energy Conversion and Management 106, 766-781.

Gao, Z., Curran, S.J., Parks II, J.E., Smith, D.E., Wagner, R.M., Daw, C.S., Edwards, K.D., Thomas, J.F., 2015b. Drive cycle simulation of high efficiency combustions on fuel economy and exhaust properties in light-duty vehicles. Applied Energy 157, 762-776.

Halbach, S., Sharer, P., Pagerit, P., Folkerts, C., Rousseau, A., 2010. Model Architecture, Methods, and interfaces for Efficient Math-Based Design and Simulation of Automotive Control Systems. SAE Technical Paper 2010-01-0241.

Knittel, C.R., 2011. Automobiles on steroids: product attribute trade-offs and technological progress in the automobile sector. Am Econom Rev 101(7), 3368-99.

Kwon, T., 2006. The determinants of the changes in car fuel efficiency in Great Britain (1978-2000). Energy Policy 34, 2405-2412.

Li, T., Gao, Y., Wang, J., Chen, Z., 2014. The Miller cycle effects on improvement of fuel economy in a highly boosted, high compression ratio, direct-injection gasoline engine: EIVC vs. LIVC. Energy Conversion and Management 79, 59-65.

Lutsey, N., Sperling, D., 2005. Energy efficiency, fuel economy, and policy implications. Transport Res Record: J Transport Res Board 1941, 8-17.

MacKenzie, D., Heywood, J.B., 2015. Quantifying efficiency technology improvements in U.S. cars from 1975-2009. Applied Energy 157, 918-928.

Moawad, A., Sharer, P., Rousseau, A., 2014. Light-duty vehicle fuel consumption displacement potential up to 2045. Report to the U.S. Department of Energy, ANL-ESD-14-4. Argonne National Laboratory, IL, April 2014.

Morisson, G.M., Chen, Y., 2011. How will changes in the ethanol market affect California's Low Carbon Fuel Standard? Transportation Research Record: Journal of the Transportation Research Board.

Parliament, E. Directorate-General For Internal Policies. http://www.europarl.europa.eu/document/activities/cont/201106/20110629ATT22885/20110629ATT 22885EN.pdf (accessed May 11, 2014). 
Papagiannaki, K., Diakoulaki, D., 2009. Decomposition analysis of CO2 emissions from passenger cars: the case of Greece and Denmark. Energy Policy 37, 3259-3267.

Pavlovic, J., Marotta, A., Ciuffo, B., 2016. CO2 emissions and energy demands of vehicles tested under the NEDC and the new WLTP type approval test procedures. Applied Energy 177, 661-670.

Sprei, F., Karlsson, S., 2013a. Energy efficiency versus gains in consumer amenities: an example from new cars sold in Sweden. Energy Policy 53, 490-499.

Sprei, F., Karlsson, S., 2013b. Shifting fuels, downsizing or both? Swedish example. Transportation Research Part D 18, 62-69.

Sprei, F., Karlsson, S., Holmberg, J., 2008. Better performance or lower fuel consumption: Technological development in Swedish new car fleet 1975-2002. Transportation Research Part D 13, 75-85.

Tietge, U., Zacharof, N., Mock, P., Franco, V., German, J., Bandivadekar, J., Ligterink, N., Lambrecht, U., 2015. From laboratory to road: A 2015 update. International Council on Clean Transportation, San Francisco, CA, September, 2015.

Togun, N.K., Baysec, S., 2010. Predicting of torque and specific fuel consumption of a gasoline engine by using artificial neural network. Applied Energy 87, 349-355.

Van den Brink, R.M., Van Wee, B., 2001. Why has car-fleet specific fuel consumption not shown any decrease since 1990? Quantitative analysis of Dutch passenger car-fleet specific fuel consumption. Transport Res Part D: Transport and Environment 13(2), 75-85.

Vijayagopal, R., Rousseau, A., 2011. System Analysis of Multiple Expert Tools. SAE Technical Paper 2011-01-0754.

Zhang, D., Zhan, Q., Chen, Y., Li, S., 2016. Joint optimization of logistics infrastructure investment and subsidies in a regional logistics network with $\mathrm{CO} 2$ emission reduction targets. Transportation Research Part D: Transport and Environment, In Press. 
Table 1. Definition of Variables

\begin{tabular}{|c|c|}
\hline Variable & Description \\
\hline $\mathbf{H P}_{\text {it }}$ & Engine power of vehicle model $\mathrm{i}$ in year $\mathrm{t}$, unit in Horsepower (HP) \\
\hline Manual $_{\text {it }}$ & Whether vehicle model $\mathrm{i}$ in year $\mathrm{t}$ has a manual transmission, 1 for Yes, 0 for No \\
\hline Diesel $_{\text {it }}$ & Whether vehicle model $\mathrm{i}$ in year $\mathrm{t}$ is a diesel engine car, 1 for Yes, 0 for No \\
\hline TurboDiesel $_{\text {it }}$ & Whether vehicle model $\mathrm{i}$ in year $\mathrm{t}$ has a turbo diesel engine, 1 for Yes, 0 for No \\
\hline TurboGasoline $_{\text {it }}$ & Whether vehicle model $\mathrm{i}$ in year $\mathrm{t}$ has a turbo gasoline engine, 1 for Yes, 0 for No \\
\hline $\mathbf{A W D}_{\text {it }}$ & Whether vehicle model $\mathrm{i}$ in year $\mathrm{t}$ has all wheel drive (AWD) feature, 1 for Yes, 0 for No \\
\hline Two-Seater $_{\text {it }}$ & Whether vehicle model $\mathrm{i}$ in year $\mathrm{t}$ is a two-seater vehicle, 1 for Yes, 0 for No \\
\hline Wagon $_{\text {it }}$ & Whether vehicle model $\mathrm{i}$ in year $\mathrm{t}$ is a wagon style vehicle, 1 for Yes, 0 for No \\
\hline Bore $_{\text {it }}$ & Diameter of the cylinder for vehicle model $\mathrm{i}$ in year $\mathrm{t}$, unit in $\mathrm{mm}$ \\
\hline $\mathbf{C R}_{\text {it }}$ & Engine compression ratio of vehicle model $\mathrm{i}$ in year $\mathrm{t}$ \\
\hline Stroke $_{\text {it }}$ & Length of engine stroke for vehicle model $\mathrm{i}$ in year $\mathrm{t}$, unit in $\mathrm{mm}$ \\
\hline Torque $_{\text {it }}$ & Torque of vehicle model i in year $\mathrm{t}$, unit in $\mathrm{Nm}$ \\
\hline VEngine $_{\text {it }}$ & Engine volume of vehicle model $\mathrm{i}$ in year $\mathrm{t}$, unit in $\mathrm{cm}^{3}$ \\
\hline
\end{tabular}

Table 2. Summary Statistics

\begin{tabular}{lllllllll}
\hline Variable & Mean & SD & Min & Max & $\begin{array}{l}\text { Mean } \\
\mathbf{1 9 8 5}\end{array}$ & $\begin{array}{l}\text { Mean } \\
\mathbf{2 0 0 2}\end{array}$ & $\begin{array}{l}\text { Mean } \\
\mathbf{2 0 0 6}\end{array}$ & $\begin{array}{l}\text { Mean } \\
\mathbf{2 0 1 5}\end{array}$ \\
\hline Passenger Car & & & & & & & & \\
FC (1/100km) & 7.32 & 1.84 & 4.2 & 11.7 & 8.45 & 8.89 & 8.27 & 5.61 \\
Weight (Kg) & 1363 & 229 & 920 & 1880 & 1280 & 1389 & 1483 & 1409 \\
HP & 154.9 & 64.4 & 67.0 & 350.0 & 123.8 & 170.8 & 201.5 & 197.7 \\
T100 (s) & 9.85 & 2.46 & 5.1 & 15.5 & 12.82 & 9.97 & 8.96 & 8.36 \\
Torque & 245.7 & 98.0 & 106.0 & 522.0 & 193.1 & 252.9 & 295.6 & 328.9 \\
VEngine & 2219 & 1009 & 425 & 8285 & 2260 & 2366 & 2538 & 2034 \\
CR & 11.7 & 3.2 & 8.8 & 19.5 & 10.8 & 11.8 & 12.00 & 12.7 \\
Diesel & 0.20 & 0.40 & 0 & 1 & 0.03 & 0.20 & 0.21 & 0.39 \\
Manual & 0.39 & 0.49 & 0 & 1 & 0.18 & 0.45 & 0.45 & 0.47 \\
AWD & 0.10 & 0.29 & 0 & 1 & 0.02 & 0.12 & 0.13 & 0.16 \\
Wagon & 0.16 & 0.37 & 0 & 1 & 0.03 & 0.28 & 0.18 & 0.24 \\
Sample Size & & & & & 387 & 627 & 728 & 624 \\
\hline
\end{tabular}

Table 3. Results of estimating regression models of passenger car fuel consumption as a function of vehicle, engine and consumer amenities parameters.

\begin{tabular}{llllll}
\hline & Model 1 & Model 2 & Model 3 & Model 4 & Model 5 \\
\hline $\ln$ (Weight) & $0.31 * * *$ & $0.58 * * *$ & $0.51 * * *$ & $0.22 * * *$ & $0.21 * * *$ \\
\hline
\end{tabular}




\begin{tabular}{|c|c|c|c|c|c|}
\hline & $(0.011)$ & $(0.009)$ & $(0.011)$ & $(0.013)$ & $(0.013)$ \\
\hline $\ln (\mathbf{H P})$ & $\begin{array}{l}0.30 * * * \\
(0.005)\end{array}$ & & & & \\
\hline $\ln (\mathrm{T} 100)$ & & $\begin{array}{l}-0.28 * * * \\
(0.006)\end{array}$ & $\begin{array}{l}-0.29 * * * \\
(0.007)\end{array}$ & & \\
\hline Manual & $\begin{array}{l}-0.07 * * * \\
(0.009)\end{array}$ & $\begin{array}{l}-0.03 * * \\
(0.010)\end{array}$ & $\begin{array}{l}-0.04 * * * \\
(0.011)\end{array}$ & $\begin{array}{l}-0.10 * * * \\
(0.009)\end{array}$ & $\begin{array}{l}-0.07 * * * \\
(0.009)\end{array}$ \\
\hline Manual*Trend & $\begin{array}{l}0.002 * * * \\
(0.000)\end{array}$ & $\begin{array}{l}0.002 * * * \\
(0.000)\end{array}$ & $\begin{array}{l}0.0003 \\
(0.0003)\end{array}$ & $\begin{array}{l}0.004 * * * \\
(0.000)\end{array}$ & $\begin{array}{l}0.003 * * * \\
(0.000)\end{array}$ \\
\hline Diesel & $\begin{array}{l}-0.27 * * * \\
(0.007)\end{array}$ & $\begin{array}{l}-0.31 * * * \\
(0.007)\end{array}$ & & $\begin{array}{l}-0.30 * * * \\
(0.012)\end{array}$ & $\begin{array}{l}-0.29 * * * \\
(0.012)\end{array}$ \\
\hline TurboDiesel & $\begin{array}{l}-0.05 * * * \\
(0.007)\end{array}$ & $\begin{array}{l}-0.05 * * * \\
(0.007)\end{array}$ & $\begin{array}{l}-0.32 * * * \\
(0.004)\end{array}$ & $\begin{array}{l}0.01 \\
(0.007)\end{array}$ & $\begin{array}{l}0.01 \\
(0.007)\end{array}$ \\
\hline TurboGasoline & $\begin{array}{l}-0.07 * * * \\
(0.004)\end{array}$ & $\begin{array}{l}-0.07 * * * \\
(0.004)\end{array}$ & $\begin{array}{l}-0.05 * * * \\
(0.004)\end{array}$ & $\begin{array}{l}-0.05 * * * \\
(0.005)\end{array}$ & $\begin{array}{l}-0.05 * * * \\
(0.005)\end{array}$ \\
\hline AWD & & & $\begin{array}{l}0.13 * * * \\
(0.018)\end{array}$ & & $\begin{array}{l}0.09 * * * \\
(0.014)\end{array}$ \\
\hline AWD*Trend & & & $\begin{array}{l}-0.002 * * * \\
(0.000)\end{array}$ & & $\begin{array}{l}-0.001 * \\
(0.000)\end{array}$ \\
\hline Two-Seater & & & $\begin{array}{l}0.12 * * * \\
(0.008)\end{array}$ & & $\begin{array}{l}0.08 * * * \\
(0.007)\end{array}$ \\
\hline Wagon & & & $\begin{array}{l}0.02 * * * \\
(0.003)\end{array}$ & & $\begin{array}{l}0.02 * * * \\
(0.003)\end{array}$ \\
\hline $\ln ($ Bore $)$ & & & & $\begin{array}{l}0.06^{*} \\
(0.023)\end{array}$ & $\begin{array}{l}0.08 * * * \\
(0.022)\end{array}$ \\
\hline $\ln (\mathbf{C R})$ & & & & $\begin{array}{l}-0.04 * \\
(0.016)\end{array}$ & $\begin{array}{l}-0.05^{* *} \\
(0.015)\end{array}$ \\
\hline $\ln ($ Stroke) & & & & $\begin{array}{l}-0.20 * * * \\
(0.017)\end{array}$ & $\begin{array}{l}-0.19 * * * \\
(0.017)\end{array}$ \\
\hline $\ln$ (Torque) & & & & $\begin{array}{l}-0.04 * * * \\
(0.010)\end{array}$ & $\begin{array}{l}-0.06 * * * \\
(0.010)\end{array}$ \\
\hline ln(VEngine) & & & & $\begin{array}{l}0.48 * * * \\
(0.012)\end{array}$ & $\begin{array}{l}0.48 * * * \\
(0.012)\end{array}$ \\
\hline Year fixed effect & Yes & Yes & Yes & Yes & Yes \\
\hline $\begin{array}{l}\text { Number of } \\
\text { observations }\end{array}$ & 18,328 & 18,328 & 18.328 & 18,328 & 18,328 \\
\hline $\mathbf{R}^{2}$ & $99.64 \%$ & $99.59 \%$ & $99.14 \%$ & $99.74 \%$ & $99.75 \%$ \\
\hline Adj. $R^{2}$ & $99.64 \%$ & $99.59 \%$ & $99.13 \%$ & $99.74 \%$ & $99.75 \%$ \\
\hline
\end{tabular}

Table 4. Comparison of technology annual improvement estimated for other European countries in literature.

\begin{tabular}{llllll}
\hline Reference & $\begin{array}{l}\text { Controlling } \\
\text { attributes }\end{array}$ & $\begin{array}{l}\text { Time } \\
\text { Period }\end{array}$ & Country & \multicolumn{2}{c}{ Annual improvement \% } \\
Kwon & Engine size & $1979-2000$ & UK & Cited Work & Our Work \\
\hline
\end{tabular}




\begin{tabular}{llllll}
\hline Sprei & $\begin{array}{l}\text { Space, accel, } \\
\text { weight }\end{array}$ & $1985-2002$ & Sweden & 2.0 & 1.5 \\
Sprei & $\begin{array}{l}\text { Space, accel, } \\
\text { weight }\end{array}$ & $1985-2008$ & Sweden & 2.4 & 2.1 \\
$\begin{array}{l}\text { Van den } \\
\text { Brink }\end{array}$ & $\begin{array}{l}\text { Weight, } \\
\text { engine size }\end{array}$ & $1985-1997$ & Netherlands & 1.3 & 0.7 \\
\hline
\end{tabular}




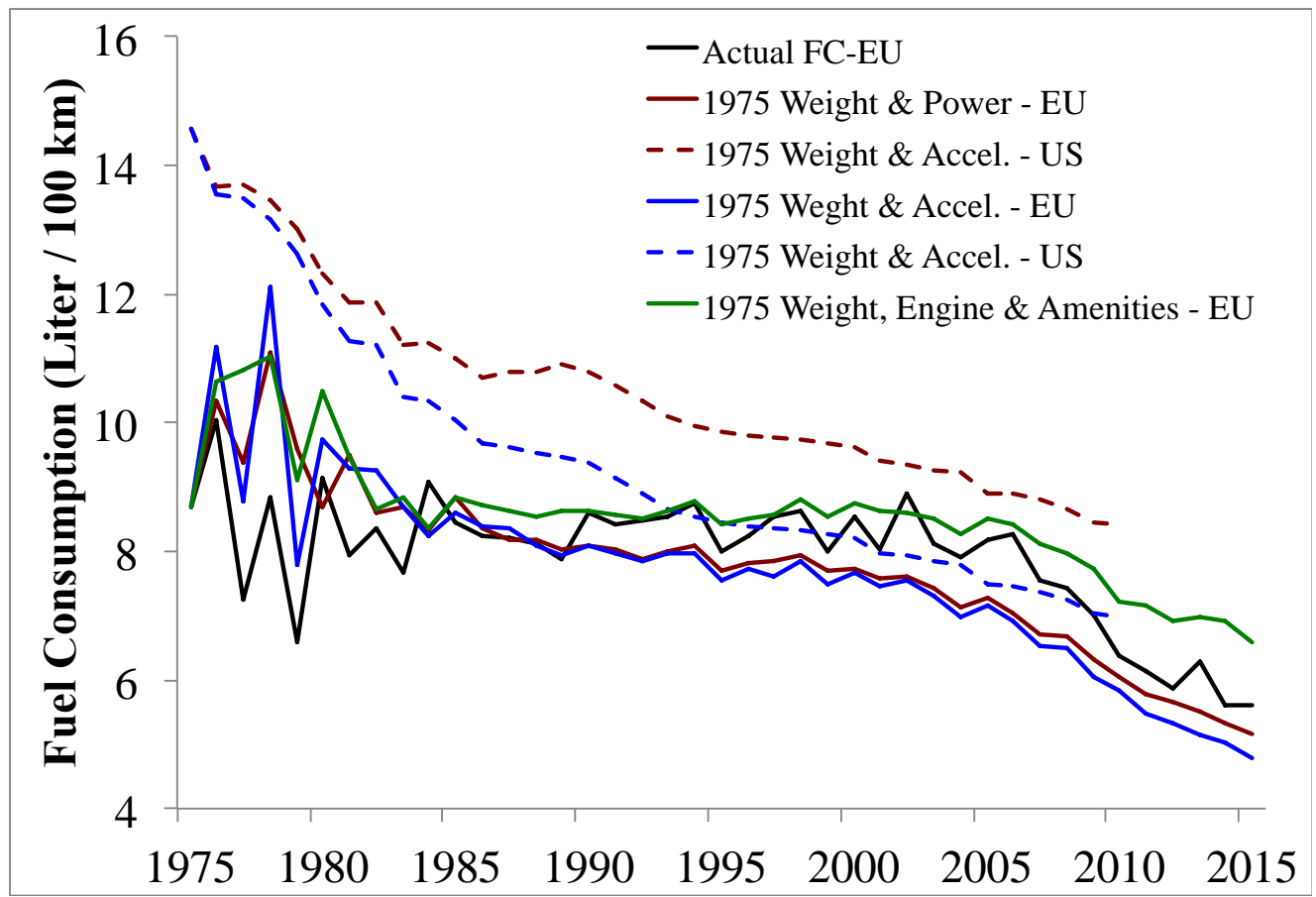

Figure 1. US and EU Real FC of average offered new European cars, and potential FC if various attributes had remained at 1975 level. 